\title{
Capacitação empresarial no Sudoeste do Paraná: uma análise do Programa Bom Negócio Paraná
}

\author{
Edson Santos Melo ${ }^{1}$, Jean Carlos Fontes ${ }^{2}$, \\ Isadora Mazzon Flessak ${ }^{3}$, Luana Rosin ${ }^{4}$
}

\begin{abstract}
Resumo: O Programa Bom Negócio Paraná (PBNP) é uma atividade de extensão, cujo foco é proporcionar capacitação empresarial gratuita aos empresários de micro e pequenas empresas, além de futuros empresários. Assim, o objetivo desse artigo é apresentar as ações e os resultados do PBNP - Núcleo Francisco Beltrão, vinculado à Universidade Estadual do Oeste do Paraná, durante o período de 2012 a 2019, na região Sudoeste do Paraná. Para tanto, recorreuse a um estudo descritivo alicerçado em dados secundários, cujo intuito foi levantar a maior série possível de informações e embasar com maior robustez os resultados. Verificou-se que, durante o período analisado, ocorreram mais de duas mil capacitações. Demonstrou-se, ainda, como é heterogêneo o perfil dos capacitados e que a satisfação com o curso se manteve sempre positiva. Além disso, a atuação do núcleo destacou-se em outras atividades, como a realização de feiras, publicações e a parceria com outros projetos de extensão. Assim, conseguiu-se evidenciar a importância do PBNP na região no período analisado.
\end{abstract}

Palavras-chave: Micro e pequenas empresas. Qualificação profissional. Empreendedorismo.

Área Temática: Educação, Políticas Públicas e Trabalho.

\section{Business training in southwestern Paraná: an analysis of the Programa Bom Negócio}

\begin{abstract}
The Bom Negócio Paraná Program (PBNP) is an extension activity, whose focus is to provide free business training to entrepreneurs of micro and small companies, as well as future entrepreneurs. Thus, the objective of this article is to present the actions and results of the PBNP - Núcleo Francisco Beltrão, linked to UniversidadeEstadual do Oeste do Paraná, from 2012 to 2019, in the southwest Paraná State. For this, was used a descriptive study based on secondary data, which aimed to raise the largest possible series of information and base the results more robustly. It was found that during the period analyzed, there were more than two thousand training. It was also demonstrated how heterogeneous the profile of the graduates is and that the satisfaction with the course always remained positive. In addition, the core activities were highlighted in other activities, such as fairs, publications and partnership with other extension projects. Therefore, it was possible to highlight the importance of PBNP in the region during the analyzed period.
\end{abstract}

Keywords: Micro and small enterprises. Professional qualification. Entrepreneurship.

\footnotetext{
${ }^{1}$ Professor do curso de Ciências Econômicas da Universidade Estadual do Oeste do Paraná, Campus de Francisco Beltrão. Endereço: Rua Maringá, no 1.200, Bairro Vila Nova, Francisco Beltrão - PR. Telefone: (46) 3520-4866. E-mail: edson.melo@unioeste.br

${ }^{2}$ Bacharel em Ciências Econômicas. E-mail: jeaancf@gmail.com.

${ }^{3}$ Graduanda em Administração da Universidade Estadual do Oeste do Paraná, Campus de Francisco Beltrão.E-mail: isadoraflessak@gmail.com.

${ }^{4}$ Graduanda em Ciências Econômicas da Universidade Estadual do Oeste do Paraná, Campus de Francisco Beltrão. E-mail: luana_rosin@hotmail.com.
} 


\section{Capacitación empresarial en el Suroeste del Paraná: un análisis del Programa Bom Negócio Paraná}

Resumen: El Programa Bom Negócio Paraná (PBNP) es una actividad de extensión, cuyo enfoque es proporcionar capacitación empresarial gratuita a losempresarios de micro y pequeñas empresas, así como a futuros empresarios. Por lo tanto, el objetivo de este trabajo es presentar lasacciones y resultados del PBNP - Núcleo Francisco Beltrão, vinculado ala Universidade Estadual do Oeste do Paraná, de 2012 a 2019, en laregiónsuroestedel Paraná. Para esto, fue utilizado unestudiodescriptivobasado en datossecundarios, cuyo objetivo era aumentar lamayorcantidadposible de información y basarlos resultados de manera más sólida. Fuepercibido que, durante el período analizado, hubo más de dos mil entrenamientos. También se demostrócuán heterogéneo es el perfil de los graduados y que lasatisfacciónconel curso siempre se mantuvo positiva. Además, lasactividadescentrales se destacaron de lasotrasactividades, como ferias, publicaciones y asociacionesconotrosproyectos de extensión. Por lo tanto, fueposibleresaltarlaimportancia de PBNP en laregión durante el período analizado.

Palabras clave: Micro y pequeñas empresas. Calificación profesional. Emprendimiento.

\section{INTRODUÇÃOO}

A representatividade dos pequenos negócios tem aumentando consideravelmente na economia brasileira. Exemplo disso é que, conforme dados do Sebrae (2019), tais empresas são responsáveis por 27\% de toda a produção de bens e serviços finais no Brasil. Todavia, a relevância de tais estabelecimentos na economia brasileira não é um fenômeno recente, já sendo verificado há algumas décadas.

Considerando a relevância dos mesmos, buscou-se editar algumas leis justamente visando dar maior segurança jurídica a tais empreendimentos. Primeiramente, a legislação procurou mitigar a situação de informalidade na qual as micro e pequenas empresas se encontravam, além de solucionar algumas questões tributárias. Dessa forma, mesmo diante do risco de incorrer em omissão de informações relevantes, cabe aqui apresentar alguns aspectos legais que definem a atividade.

No ano de 2006, instituiu-se o Estatuto Nacional da Microempresa e da Empresa de Pequeno Porte (BRASIL, 2006), o qual estabeleceu que uma microempresa ou empresa de pequeno porte é aquela que auferir receita bruta igual ou inferior a $\mathrm{R} \$ 360.000,00$ (se for microempresa) e, no caso da empresa de pequeno porte, auferir, em cada ano-calendário, receita bruta superior a $\mathrm{R} \$ 360.000,00$ e igual ou inferior a $\mathrm{R} \$ 4.800 .000,00$. Posteriormente, em 2008, com a publicação da Lei Complementar $n^{\circ} 128$, criou-se a figura do Microempreendedor Individual - MEI (BRASIL, 2008). Basicamente, para ser um MEI, o empresário não pode participar como sócio de outra empresa, além de poder contratar apenas um empregado pagando a remuneração de um salário mínimo ou piso salarial da categoria. Além disso, conforme BRASIL (2016), para se enquadrar como MEI, deve-se respeitar um teto máximo de receita bruta anual equivalente a $\mathrm{R} \$ 81.000,00$.

Uma vez realizadas as devidas caracterizações dos tipos de pequenos negócios legalmente existentes no Brasil, é oportuno trazer alguns números que reforçam a importância de tais empreendimentos no país. De acordo com o relatório do Global Entrepreneurship Monitor - GEM (2018), os pequenos negócios representavam $99 \%$ dos estabelecimentos do país e geravam 54\% de todos os empregos formais. Dados mais recentes indicam a existência de 15,4 milhões de estabelecimentos de pequeno porte no Brasil, sendo 
estes distribuídos da seguinte forma: 8,6 milhões são microempreendedores individuais e 6,8 milhões são micro e pequenas empresas (SEBRAE, 2019).

Além disso, ainda conforme dados do Sebrae (2019), alguns outros pontos merecem ser pontuados, a saber: i) São nos pequenos negócios que estão concentrados os empreendedores mais jovens; ii) A mortalidade das empresas após os dois primeiros anos reduziu, mas ainda está em um nível elevado (23,4\%), ou seja, a cada quatro pequenos negócios abertos, um fechará as portas; iii) Em dez anos, a média salarial dos trabalhadores dos pequenos negócios subiu $25 \%$ acima da inflação. Sobre esse ponto, em comparação, no mesmo período, a média nas empresas de maior porte ficou na faixa de 14\%, ainda que, em valores brutos, nessas últimas a remuneração seja maior; e iv) Quanto à escolaridade dos microempreendedores, entre os homens predominavam o ensino médio completo ou superior incompleto (36,9\%), enquanto que $44,2 \%$ das mulheres possuíam ensino superior completo.

Foi diante do contexto nacional de regulação e incentivo ao empreendedorismo que, em 2005, a prefeitura de Curitiba criou o Programa Bom Negócio. Até então, o projeto tinha como propósito fomentar o desenvolvimento através de capacitação e apoio ao pequeno e microempreendedor dos setores industrial, comercial e de serviço. Em 2012, o governo do Estado do Paraná resolveu expandir o projeto para as demais regiões do estado, nomeando-o de Programa Bom Negócio Paraná (PBNP). À época, o acordo de cooperação envolveu seis secretarias, agências de fomento, federações e demais entidades. No entanto, a concretização do projeto por todo o estado só seria viável diante de parcerias que apresentassem capacidade técnica e que tivessem facilidade para realizar o curso na maioria dos municípios paranaenses. Então, recorreu-se às sete universidades estaduais paranaenses para que, sob edital específico elaborado pela Secretaria de Ciência, Tecnologia e Ensino Superior ${ }^{1}$ (SETI), fosse possível a viabilização do projeto. Ao todo, foram implantados quatorze núcleos, sendo os municípios alocados conforme a área de atuação de cada universidade e seus respectivos campi.

Em comum a todos os núcleos do PBNP, tem-se o objetivo de contribuir para o desenvolvimento econômico e social dos municípios onde atuam, por meio da capacitação empresarial gratuita aos empresários proprietários das micro e pequenas empresas e também aos microempreendedores individuais (MEIs), visando o crescimento desses negócios para a geração de emprego e renda local. Todo o processo de capacitação pode acontecer por meio de duas modalidades de curso: presencial e a distância (EaD). Em ambas as modalidades se trabalham os módulos de gestão de negócios, gestão comercial, gestão financeira, gestão de pessoas e gestão estratégica, tudo isso distribuído em uma carga horária de 66 horas no curso presencial e 68 horas no EaD. Observa-se que tanto as cargas horárias quanto os conteúdos trabalhados em cada um dos módulos são padronizados entre todos os núcleos, que seguem rigorosamente instruções e metodologias especificadas pelo governo do estado. Porém, ainda assim, há flexibilização para cada núcleo complementar o material conforme o perfil da turma. 
Quatro linhas principais norteiam as ações do PBNP desde sua idealização: i) Ensinar, capacitar e orientar os empreendedores, formais ou não, das micro, pequenas e médias empresas em todos os municípios do Paraná; ii) Financiar projetos que venham promover o desenvolvimento local por meio de ações de orientação técnica e capacitação a empreendedores de setores estratégicos da sociedade; iii) Criação de emprego e geração de renda, fortalecendo atividades empreendedoras nos municípios; iv) Estimular a formalização de empresas.

Além disso, enfatiza-se que o PBNP está diretamente associado à extensão universitária, e sua capacitação só se torna possível devido uma ampla interação entre a universidade e os demais setores da sociedade. Nesse aspecto, reforça-se o entendimento de que:

(...) a extensão é uma via de mão-dupla, com trânsito assegurado à comunidade acadêmica, que encontrará, na sociedade, a oportunidade de elaboração da práxis de um conhecimento acadêmico. No retorno à Universidade, docentes e discentes trarão um aprendizado que, submetido à reflexão teórica, será acrescido àquele conhecimento. Esse fluxo, que estabelece a troca de saberes sistematizados, acadêmico e popular, terá como consequências a produção do conhecimento resultante do confronto com a realidade brasileira e regional, a democratização do conhecimento acadêmico e a participação efetiva da comunidade na atuação da Universidade (FORPROEX, 1987, p.11).

Observa-se, ainda, que a atuação do PBNP está inteiramente em consonância com a Política Nacional de Extensão Universitária, a qual destaca que "a extensão universitária sob o princípio constitucional da indissociabilidade entre ensino, pesquisa e extensão, é um processo interdisciplinar, educativo, cultural, científico e político que promove a interação transformadora entre universidade e outros setores da sociedade" (FORPROEX, 2012). Ainda conforme Dalcin e Augustin (2016), a universidade é a detentora do conhecimento científico, cabendo a ela transmiti-lo por meio do ensino. Segundo os referidos autores, para além disso, por intermédio da pesquisa, tais conhecimentos são aprimorados e, consequentemente, surgirão outros, que, por meio da extensão, deverão ser difundidos, socializados e democratizados à comunidade.

\section{OBJETIVOS}

À luz do exposto, esse artigo tem por objetivo apresentar as ações e os resultados do Programa Bom Negócio Paraná - Núcleo Francisco Beltrão, vinculado à Universidade Estadual do Oeste do Paraná (Unioeste). Para tanto, serão analisados resultados de agosto de 2012 a junho de 2019. Vale observar que a Unioeste possui cinco campi: Cascavel, Francisco Beltrão, Marechal Cândido Rondon, Foz do Iguaçu e Toledo. Em todos os campi se encontram instalados um núcleo do Programa Bom Negócio Paraná. O PBNP - Núcleo Francisco Beltrão situa-se na mesorregião Sudoeste do Paraná, cuja região de atuação compreende 42 municípios ao todo.

\section{METODOLOGIA}

Nesta seção serão destacados dois aspectos metodológicos importantes. Inicialmente, explicitar-se-á o procedimento pelo qual ocorre a intervenção do Programa Bom Negócio Paraná diretamente na comunidade e, após isto, finalizando o tópico, será especificado o método adotado quanto à abordagem, levantamento e análise dos dados. 
O Programa Bom Negócio Paraná fundamenta-se, basicamente, na realização de curso de capacitação empresarial para microempreendedores individuais, empresários de pequenas e médias empresas, futuros empresários, além das pessoas que trabalham como autônomos ou na informalidade. Conforme já indicado na seção anterior, a capacitação ocorre tanto na modalidade presencial quanto na modalidade de ensino a distância. Dessa forma, para que o projeto seja viável, além de recursos financeiros para custear toda parte operacional, necessita-se de uma equipe específica e capacitada, cuja seleção ocorre por edital próprio, orientado pela SETI. Atualmente, a equipe é composta por dois docentes efetivos (sendo um coordenador e outro orientador), três bolsistas recém-formados de nível superior (profissionais com no máximo três anos de formado) e três bolsistas graduandos (que executam o trabalho operacional), todos das áreas de Administração ou Ciências Econômicas.

Contudo, antes de se iniciar uma turma presencial, faz-se necessário uma extensa rede de contatos e interesses em comum nos municípios. Geralmente, é comum o engajamento da prefeitura, associação comercial, agentes de crédito, agentes de desenvolvimento local, entre outros. Tal rede é de fundamental importância, pois, além de disponibilizar o local do curso, é de competência do município formalizar as inscrições dos interessados. Uma vez atingido o número médio de 35 alunos, inicia-se a turma presencial no município. Destaca-se, ainda, que não há custo algum aos participantes ou ao município. Todo o custeio operacional com o projeto, incluindo material gráfico, combustível, material de expediente e, caso necessário, hospedagem e alimentação aos instrutores, estão contemplados no financiamento do projeto, sendo tal recurso gerido pela Unioeste, por meio de convênio próprio firmado com a SETI e o Governo do Estado.

Didaticamente, o curso de extensão do Programa Bom Negócio Paraná está estruturado em cinco módulos: gestão de negócios, gestão comercial, gestão financeira, gestão de pessoas e gestão estratégica. Em tais módulos são ministrados conceitos básicos de gestão empresarial, além de se trabalhar atividades práticas como objetivo de reforçar e facilitar a compreensão do conteúdo. Com isso, busca-se permitir que, já no dia posterior a aula, o aluno consiga aplicar em seu ambiente de trabalho os conceitos e as ferramentas de gestão estudadas.

No total, o curso compreende um período médio de cinco semanas, sendo trabalhado um módulo por semana, sempre no horário noturno. Com exceção do módulo de gestão financeira, o qual é realizado em quatro dias, os demais são ministrados em três dias na semana. Por praticidade, os módulos estão reunidos em uma única apostila, a qual é fornecida gratuitamente aos participantes. Não há a opção de o participante cursar apenas um módulo de sua escolha. Além disso, apenas está apto a concluir curso e receber certificado o participante que apresentar uma frequência mínima de $75 \%$ do total de 66 horas.

Desde o ano de 2015, além da opção presencial, oferta-se também a modalidade EaD. O conteúdo dessa modalidade é o mesmo do curso presencial, o qual é adaptado para uma plataforma digital própria da Unioeste e distribuído em quatorze unidades, com carga horária total de 68 horas. Na modalidade EaD, o aluno, obrigatoriamente, tem de cursar um módulo de introdução ao ambiente virtual, com carga horária de duas horas, tudo para familiarizá-lo à plataforma. 
Ao participante que concluiu o curso presencial, mas que, por algum motivo, avalia que ficou uma lacuna em algum tópico específico abordado no curso ou está tendo alguma dificuldade de aplicação prática dos conteúdos estudados nos módulos, é facultado a solicitação de uma orientação técnica, a qual consiste em quatro etapas: na primeira etapa o participante capacitado identifica a área na qual deseja a orientação (sempre de acordo com os conteúdos trabalhados no curso). Feita a solicitação, na segunda etapa, uma equipe (no mínimo dois instrutores) se desloca até o estabelecimento, onde é realizado uma avaliação da situação e coleta de dados. Na terceira etapa, o problema de cada empresa é debatido de forma minuciosa internamente no PBNP - Núcleo Francisco Beltrão e, depois disso, elabora-se um relatório final com a avaliação do cenário e possíveis soluções. Na quarta e última etapa, os instrutores retornam à empresa e apresentam o relatório com as sugestões de melhorias. Além disso, é comum os instrutores realizarem um acompanhamento por mais uma ou duas semanas para verificarem a efetividade das orientações e garantirem a aplicabilidade correta das mesmas.

Uma vez apresentada a forma de como ocorre as ações do PBNP - Núcleo Francisco Beltrão, cabe agora, visando atender o objetivo proposto, delinear o procedimento metodológico do artigo. Para tanto, optouse por um estudo descritivo, com procedimento fundamentado em uma pesquisa documental, na qual grande parte das informações foram obtidas por meio de dados internos ao projeto.

Conforme Oliveira (1997), “o estudo descritivo possibilita o desenvolvimento de um nível de análise em que se permite identificar diferentes formas de fenômenos", assim também como ordená-los e classificá-los. Para Gil (2010), a pesquisa descritiva tem como objetivo a descrição das características de determinada população, tendo como exemplo aquelas que se pretendem estudar as características de um grupo. Rampazzo (2013) destaca que a pesquisa descritiva deve observar, registrar, analisar e correlacionar os dados, sem manipulá-los. O último autor citado ainda observa que é comum no desenvolvimento desse tipo de estudo a utilização de dados e registros que não constam em publicações.

Os dados utilizados para demonstrar a atuação do PBNP - Núcleo Francisco Beltrão foram obtidos por meio de uma pesquisa documental. Conforme Cellard (2008), a análise documental favorece a observação do processo de maturação ou de evolução de indivíduos, grupos, entre outros. Por sua vez, Gil (2010) assenta que a possibilidade de pesquisas documentais ex-post-facto, isto é, aquelas elaboradas a partir de fato passado com base em dados disponíveis e submetidas a tratamento estatístico, sendo que algumas vezes podem até se assemelhar a levantamentos, diferindo destes devido ao fato de serem elaboradas com os dados disponíveis. Ademais, Zanella (2013) observa que a pesquisa documental deve se valer de materiais que ainda não receberam um tratamento analítico, podendo envolver a investigação em documentos internos, apresentando como vantagens a disponibilidade das informações e o baixo custo.

Dessa forma, para a execução desse trabalho, embasou-se, fundamentalmente, na coleta de informações e o levantamento de dados secundários, sendo esses oriundos de dois questionários estruturados pela SETI: o primeiro aplicado ao participante antes do início do curso e o segundo no dia do encerramento. Após alimentadas em uma planilha, as respostas dos questionários ficam arquivadas, com compartilhamento conjunto 
entre a SETI e o PBNP - Núcleo Francisco Beltrão. Com isso, necessitou-se de uma ampla revisão da base de dados interna, uma vez que, devido a troca de sistemas, alguns dados se perderam internamente, principalmente os relativos ao ano de 2012. Após reunir todas as informações de cada participante e sua respectiva turma, passou-se para a etapa de tabulação e análise dos dados, tudo isso visando a demonstração do perfil dos capacitados e a atuação do PBNP - Núcleo Francisco Beltrão, durante o período de agosto de 2012 a junho de 2019.

\section{RESULTADOS E DISCUSSÃO}

Este tópico concentrará a apresentação de alguns resultados principais selecionados a fim de evidenciar a atuação do PBNP - Núcleo Francisco Beltrão, enquanto projeto de extensão na região Sudoeste do Paraná, entre o período de agosto de 2012 a junho de 2019. Para tanto, primeiramente, apresenta-se na Tabela 1, o número de concluintes considerando as modalidades presencial e EaD, além de separá-los conforme o sexo. Observa-se que os dados relativos a agosto de 2012 a junho de 2013 foram fornecidos pela SETI-PR, pois, na época, tais informações eram alimentadas em um banco de dados específico online, o qual, depois de um período foi retirado de operação.

Tabela 1 - Número de capacitados pelo PBNP - Núcleo Francisco Beltrão, nas modalidades presencial e ensino a distância, no período $2012-2019$

\begin{tabular}{|l|c|c|c|c|c|}
\hline \multirow{2}{*}{ Período } & \multicolumn{4}{|c|}{ Concluintes } & \multirow{2}{*}{ Total } \\
\cline { 2 - 5 } & \multicolumn{2}{|c|}{ Presencial } & \multicolumn{2}{c|}{ EaD } & \\
\cline { 2 - 5 } & Feminino & Masculino & Feminino & Masculino & 388 \\
\hline $2012-2013$ & - & - & - & - & 284 \\
\hline 2013 & 139 & 145 & - & - & 363 \\
\hline 2014 & 222 & 141 & - & 15 & 190 \\
\hline 2015 & 85 & 65 & 25 & 14 & 290 \\
\hline 2016 & 147 & 105 & 24 & 9 & 267 \\
\hline 2017 & 148 & 93 & 17 & 3 & 219 \\
\hline 2018 & 123 & 87 & 6 & 11 & 183 \\
\hline 2019 & 104 & 51 & 89 & 52 & 2184 \\
\hline Total & 968 & 687 & & & - \\
\hline
\end{tabular}

Fonte: Elaborado pelos autores.

De uma forma geral, nota-se que o PBNP - Núcleo Francisco Beltrão atuou de forma bastante efetiva na região, uma vez que, no total, mais de dois mil de empresários e futuros empresários foram capacitadas em gestão empresarial. Cabe destacar que a região de atuação do programa apresenta algumas disparidades, sendo que, segundo o Instituto Brasileiro de Geografia e Estatística - IBGE (2019a), de um total de 42 municípios, 10 
possuem população inferior a 5 mil habitantes. Ainda assim, realizaram-se 77 turmas presenciais em 28 municípios da região, com destaque para o município de Francisco Beltrão, no qual aconteceram 27 turmas presenciais. Quanto ao EaD, totalizaram-se 13 turmas no período de 2015 a 2019.

Sobre a realização das turmas presencias, vale reforçar que o PBNP tem sua ação orientada essencialmente no que se espera de um projeto de extensão, ou seja, a estreita inter-relação entre universidade e demais setores da sociedade. Somente com essa rede de inter-relações bem estabelecidas é que se viabiliza a implantação de uma turma presencial com sucesso. Caso algum elo dessa rede seja rompido, diminui-se a probabilidade de implantação do curso na localidade.

Além da questão referenciada acima, outros fatores também podem interferir na realização das turmas e, por consequência, no número de capacitados pelo PBNP - Núcleo Francisco Beltrão. Dentre tais fatores, podese discutir pontualmente alguns resultados, como, por exemplo, o maior número de capacitados entre os anos de 2012 a 2014, justificado pela quantidade de membros da equipe constituída no período. Os editais de financiamentos daqueles anos especificavam que, afora o coordenador, o orientador e os três bolsistas de graduação, o PBNP - Núcleo Francisco Beltrão contava com cinco bolsistas recém-formados, os quais atuavam como instrutores, ministrando diretamente as capacitações. Por conseguinte, com um maior número de instrutores, maior era a facilidade em dinamizar o processo de capacitação, de modo que, em alguns períodos, foi possível a realização de três turmas simultâneas em cidades diferentes.

Em 2015, o edital de financiamento do projeto foi modificado, e mesmo com o programa planejando uma expansão de sua atuação, a SETI reduziu os recursos financeiros para custeio. Com isso, o quadro de instrutores diminuiu, passando de cinco bolsistas recém-formados para quatro. Ainda no referido ano ocorreu uma greve nas instituições públicas de ensino superior do Paraná, a qual durou mais de dois meses e interrompeu as atividades de praticamente todos os projetos de extensão. No caso do PBNP, por questões operacionais, a equipe não tinha condições de se deslocar até os municípios para realizar o curso. Reflexo de tudo isso foi o menor número de capacitados em todos os anos de atuação do PBNP - Núcleo Francisco Beltrão. Todavia, é importante observar que foi justamente nessa época que entrou em operação a experiência com a modalidade de ensino a distância.

Em 2016, o número de capacitados aumentou consideravelmente, visto que o cenário se mostrou mais positivo naquele ano. O resultado pode ser verificado pelo aumento de $53 \%$ no número de capacitados. Como estratégia interna, naquele ano, o PBNP - Núcleo Francisco Beltrão buscou intensificar as parcerias nos municípios, além de reforçar sua atuação nas redes sociais, o que resultou no envolvimento de um grande número de seguidores por toda região. Todavia, em 2017, a equipe foi novamente reduzida, ficando com apenas três instrutores. Mesmo assim, conseguiu-se manter o número de capacitações, dado que se observou uma redução de apenas 7,93\% de capacitados em relação período anterior.

Ainda com base na Tabela 1, percebe-se uma redução no número de capacitados no ano de 2018, o que ocorreu devido a dois fatores, quais sejam: i) o início tardio de operação do programa, ocorrido em no mês de 
abril, devido ao atraso no edital e liberação de recurso financeiro por parte do governo estadual; ii) o período eleitoral. Esse último merece uma análise à parte. Como todo processo de início de turma nos municípios acontece diretamente com o envolvimento de pessoas e setores ligados à administração pública, é comum durante o período eleitoral que os mesmos priorizem atuarem nas campanhas. Portanto, enfraquece-se um elo no processo de formação de turmas presenciais, restando ao PBNP - Núcleo Francisco Beltrão direcionar seus esforços nas turmas de EaD. Entretanto, o ano de 2019 indicou uma retomada forte do número de capacitados, visto que, até o mês de junho, somente na modalidade presencial, capacitou-se aproximadamente $74 \%$ do total relativo aos 12 meses anteriores.

Em relação à modalidade $\mathrm{EaD}$, a análise isolada quanto ao número de pessoas capacitadas torna-se mais complexa. Em linhas gerais, como pode ser visto na Tabela 1, o número de capacitados é bem inferior ao da modalidade presencial. Ademais, esta é a modalidade que apresenta o maior número de evasão entre os matriculados. No entanto, tal evasão decorre de diversos motivos, sendo os mais relatados: i) dificuldade de navegação pela plataforma utilizada para a realização do curso, o que acaba prejudicando a realização das atividades e, consequentemente, afetando o processo de aprendizagem; e, ii) falta de tempo, mesmo o curso sendo inteiramente flexível em relação ao horário, pois está estruturado de forma que o aluno possa acessá-lo a qualquer momento. Entretanto, caso o aluno atrase alguma atividade e não consegue repor o conteúdo dentro do prazo estipulado, em grande medida, acontece a desistência do curso. Todavia, destaca-se que mais de $90 \%$ dos concluintes afirmaram que o conteúdo excedeu positivamente a expectativa ou estava dentro do esperado. $\mathrm{Na}$ modalidade presencial tal percentual de satisfação ficou na média de $97 \%$ durante todo o período.

Uma última análise que cabe ser feita é quanto à diferença entre o número de mulheres e homens capacitados (Tabela 1). Em quase todos os períodos e modalidades foi perceptível a superioridade no número de mulheres que buscaram capacitação em gestão empresarial, na região Sudoeste do Paraná. Durante o período que se tem os dados tabulados, no total, 968 mulheres foram capacitadas até junho de 2019, enquanto o número de homens capacitados foi de 687. Tais números corroboram o que se tem identificado no cenário nacional, pois dados do Sebrae (2019) revelam que 51,5\% dos novos empreendimentos nacionais estão sendo comandados por pessoas do sexo feminino.

Diante das estatísticas apresentadas acima, faz-se importante demostrar, também, quão heterogêneas são as turmas do PBNP. Para isso, serão apresentadas algumas informações que relatam tal diversificação, cujo foco centrar-se-á sobre o perfil dos participantes. Em primeiro lugar, na Tabela 2, pode-se analisar a faixa etária dos participantes capacitados em cada uma das duas modalidades. Observa-se que, por falta de dados detalhados conforme já relatado anteriormente, desta tabela em diante, toda análise partirá do ano de 2013.

Em relação à capacitação presencial, percebe-se que, com exceção dos anos de 2014 e 2015, o percentual de capacitados com idade entre 35 a 64 anos sempre foi superior às demais faixas, apesar de a faixa de 25 a 34 anos também apresentar alto percentual. Lembra-se que, conforme apresentado anteriormente, na região Sudoeste 
do Paraná, as mulheres correspondem ao maior efetivo que concluem a capacitação. Ademais, ocorre uma similaridade dos capacitados na região com os empresários nacionais, já que de acordo com o GEM (2018), pessoas na faixa etária de 25 a 34 anos foram as mais ativas no processo de criação de novos negócios no país.

Quanto aos jovens (18 a 24 anos), ainda considerando a modalidade presencial, apesar de a participação ter reduzido em 2016 e 2017, ocorreu uma elevação significativa nos anos de 2018 e 2019, o que também é observado entre aqueles que possuem até 18 anos. Nesta questão, três pontos se destacam. O primeiro diz respeito ao jovem que já tinha um planejamento de possuir seu próprio negócio e, dessa maneira, está buscando se capacitar. O segundo caso é relativo ao jovem que está desempregado, sendo que, em grande proporção, isso é reflexo do cenário econômico nacional. Muitos dos desempregados que se situam nesse perfil são forçados a encontrarem alternativas ao desemprego visando à obtenção de uma renda mínima, sendo que muitas dessas alternativas se relacionam ao empreendedorismo por necessidade. Já o terceiro caso contempla os jovens que procuram o curso porque a empresa o inscreveu ou apenas para melhorar o currículo.

Tabela 2 - Faixa etária dos capacitados pelo PBNP - Núcleo Francisco Beltrão, nas modalidades presencial e ensino a distância, no período 2013 -2019

\begin{tabular}{|c|c|c|c|c|c|}
\hline \multicolumn{6}{|c|}{ Presencial } \\
\hline $\begin{array}{l}\text { Período/ } \\
\text { faixa etária }\end{array}$ & até 18 anos & 18 a 24 anos & 25 a 34 anos & 35 a 64 anos & 65 anos ou mais \\
\hline 2013 & $1,13 \%$ & $18,05 \%$ & $27,82 \%$ & $52,63 \%$ & $0,38 \%$ \\
\hline 2014 & $3,48 \%$ & $18,26 \%$ & $39,13 \%$ & $38,84 \%$ & $0,29 \%$ \\
\hline 2015 & $10,49 \%$ & $21,68 \%$ & $34,27 \%$ & $33,57 \%$ & $0,00 \%$ \\
\hline 2016 & $8,80 \%$ & $15,60 \%$ & $34,40 \%$ & $40,40 \%$ & $0,80 \%$ \\
\hline 2017 & $2,52 \%$ & $12,18 \%$ & $36,97 \%$ & $48,32 \%$ & $0,00 \%$ \\
\hline 2018 & $3,37 \%$ & $23,56 \%$ & $20,67 \%$ & $24,52 \%$ & $1,44 \%$ \\
\hline 2019 & $4,58 \%$ & $32,03 \%$ & $28,10 \%$ & $33,33 \%$ & $1,96 \%$ \\
\hline Total & $5,18 \%$ & $18,84 \%$ & $34,19 \%$ & $41,36 \%$ & $0,44 \%$ \\
\hline \multicolumn{6}{|c|}{ Ensino a distância } \\
\hline $\begin{array}{l}\text { Período/ } \\
\text { faixa etária }\end{array}$ & até 18 anos & 18 a 24 anos & 25 a 34 anos & 35 a 64 anos & 65 anos ou mais \\
\hline 2015 & - & $60,00 \%$ & $27,50 \%$ & $12,50 \%$ & $0,00 \%$ \\
\hline 2016 & - & $60,26 \%$ & $26,92 \%$ & $12,82 \%$ & $0,00 \%$ \\
\hline 2017 & - & $38,46 \%$ & $46,15 \%$ & $15,38 \%$ & $0,00 \%$ \\
\hline 2018 & - & $44,44 \%$ & $44,44 \%$ & $11,11 \%$ & $0,00 \%$ \\
\hline 2019 & - & $56,79 \%$ & $32,26 \%$ & $10,95 \%$ & $0,00 \%$ \\
\hline Total & - & $51,99 \%$ & $35,46 \%$ & $12,55 \%$ & $0,00 \%$ \\
\hline
\end{tabular}

Fonte: Elaborado pelos autores. 
No que tange ao número de capacitados no EaD, observa-se a enorme diferença da faixa etária do público capacitado pelo PBNP - Núcleo Francisco Beltrão, com destaque aos jovens de 18 a 24 anos (51,99\%), enquanto a participação de pessoas de 65 anos de idade ou mais é nula. Destarte, tão importante quanto verificar a faixa etária, faz-se pertinente também conhecer a escolaridade de todos os concluintes do PBNP - Núcleo Francisco Beltrão, informação apresentada na Tabela 3, a seguir.

Conforme a Tabela 3, pode-se constatar que os capacitados na modalidade presencial pelo PBNP Núcleo Francisco Beltrão possuíam o ensino médio completo, seguido por aqueles que possuíam o ensino superior. Todavia, ainda ao longo do período analisado, havia pessoas com ensino fundamental, ensino técnico e pós-graduação. Aqui se apresenta um dos grandes desafios que a equipe de instrutores tinha em cada turma, pois os mesmos eram desafiados em cada aula a fazerem com que todos na turma conseguissem acompanhar os conteúdos ministrados, independente do grau de escolaridade ou experiência acerca do assunto.

Tabela 3 - Escolaridade dos capacitados pelo PBNP - Núcleo Francisco Beltrão, nas modalidades presencial e ensino a distância, no período 2013 - 2019

\begin{tabular}{|l|c|c|c|c|c|}
\hline \multicolumn{7}{|c|}{ Presencial } \\
\hline Período & Fundamental & Médio & Técnico & Superior & Pós-graduação \\
\hline 2013 & $19,29 \%$ & $48,57 \%$ & $7,14 \%$ & $17,14 \%$ & $7,86 \%$ \\
\hline 2014 & $15,28 \%$ & $42,36 \%$ & $5,56 \%$ & $23,61 \%$ & $13,19 \%$ \\
\hline 2015 & $13,10 \%$ & $53,79 \%$ & $13,79 \%$ & $13,79 \%$ & $5,52 \%$ \\
\hline 2016 & $13,75 \%$ & $50,00 \%$ & $5,83 \%$ & $25,42 \%$ & $5,00 \%$ \\
\hline 2017 & $8,62 \%$ & $41,81 \%$ & $10,34 \%$ & $26,29 \%$ & $12,93 \%$ \\
\hline 2018 & $8,21 \%$ & $47,83 \%$ & $7,73 \%$ & $27,05 \%$ & $9,18 \%$ \\
\hline 2019 & $6,62 \%$ & $42,38 \%$ & $5,96 \%$ & $37,09 \%$ & $7,95 \%$ \\
\hline \multicolumn{7}{|c|}{ Ensino a distância } \\
\hline Período & Fundamental & Médio & Técnico & Superior & Pós-graduação \\
\hline 2015 & $0,00 \%$ & $7,69 \%$ & $0,00 \%$ & $76,92 \%$ & $15,38 \%$ \\
\hline 2016 & $2,63 \%$ & $5,26 \%$ & $0,00 \%$ & $81,58 \%$ & $10,53 \%$ \\
\hline 2017 & $0,00 \%$ & $0,00 \%$ & $0,00 \%$ & $73,08 \%$ & $26,92 \%$ \\
\hline 2018 & $0,00 \%$ & $0,00 \%$ & $0,00 \%$ & $77,78 \%$ & $22,22 \%$ \\
\hline 2019 & $0,00 \%$ & $0,00 \%$ & $0,00 \%$ & $84,36 \%$ & $15,64 \%$ \\
\hline
\end{tabular}

Fonte: Elaborado pelos autores.

Não raro, já se verificou a participação de empreendedores que não possuíam o ensino fundamental completo, havendo até casos em que o aluno não apresentava domínio mínimo da escrita e da leitura, necessitando, desse modo, de atenção especial dos instrutores para prosseguir no curso. Contudo, averiguou-se que não 
houve desistência dos participantes nas condições relatadas em virtude de tal fato. Ao contrário, com esforço e perseverança, sempre surpreenderam e motivaram a turma. Já em relação ao $\mathrm{EaD}$, foi majoritária a participação das pessoas com ensino superior completo (completo ou cursando), além de pós-graduados. Em contraste, dados do GEM (2018) apontam que aproximadamente 25,7 milhões de empresários no Brasil possuem apenas o ensino fundamental (14,6 milhões com fundamental incompleto e 11,1 milhões com fundamental completo). Porém, a importância do ensino superior na condução de um negócio fica evidente quando analisadas algumas estatísticas do IBGE (2019b), as quais demonstram que entre as empresas que deixaram o mercado, 92,4\% não possuíam pessoal com curso superior, contra 7,6\% das que detinham pessoal com curso superior.

Complementando a descrição do perfil dos profissionais que buscaram capacitação em gestão empresarial pelo PBNP - Núcleo Francisco Beltrão, apresenta-se a seguir, na Tabela 4, a classificação conforme a ocupação dos participantes. Observa-se que, neste caso, os dados reúnem informações agregadas das modalidades presencial e EaD.

Tabela 4 - Classificação da ocupação dos capacitados pelo PBNP - Núcleo Francisco Beltrão, no período $2013-2019$

\begin{tabular}{|l|c|c|c|c|c|c|}
\hline Período & $\begin{array}{c}\text { Proprietário } \\
\text { (empresa } \\
\text { formal) }\end{array}$ & $\begin{array}{c}\text { Proprietário } \\
\text { (empresa } \\
\text { informal) }\end{array}$ & $\begin{array}{c}\text { Funcionário } \\
\text { com carteira } \\
\text { assinada }\end{array}$ & $\begin{array}{c}\text { Funcionário } \\
\text { sem carteira } \\
\text { assinada }\end{array}$ & Desempregado & Autônomo \\
\hline 2013 & $49,26 \%$ & $8,09 \%$ & $24,63 \%$ & $4,78 \%$ & $4,41 \%$ & $8,09 \%$ \\
\hline 2014 & $43,71 \%$ & $2,10 \%$ & $34,62 \%$ & $6,99 \%$ & $4,90 \%$ & $6,99 \%$ \\
\hline 2015 & $47,79 \%$ & $2,21 \%$ & $27,94 \%$ & $3,68 \%$ & $5,88 \%$ & $12,50 \%$ \\
\hline 2016 & $45,16 \%$ & $2,76 \%$ & $28,57 \%$ & $3,23 \%$ & $8,76 \%$ & $10,14 \%$ \\
\hline 2017 & $45,69 \%$ & $3,88 \%$ & $25,86 \%$ & $3,88 \%$ & $8,62 \%$ & $10,34 \%$ \\
\hline 2018 & $45,64 \%$ & $3,08 \%$ & $21,54 \%$ & $5,64 \%$ & $13,33 \%$ & $9,23 \%$ \\
\hline 2019 & $31,33 \%$ & $1,03 \%$ & $38,67 \%$ & $6,67 \%$ & $7,33 \%$ & $11,33 \%$ \\
\hline Total & $44,27 \%$ & $3,60 \%$ & $28,40 \%$ & $5,00 \%$ & $7,56 \%$ & $9,33 \%$ \\
\hline
\end{tabular}

Fonte: Elaborado pelos autores.

Pela Tabela 4, percebe-se que, em média, 44,27\% de todos os capacitados em gestão empresarial pelo PBNP compreende a categoria dos proprietários de empresas formalizadas, seguido por funcionário com carteira assinada $(28,40 \%)$ e autônomo $(9,33 \%)$. A participação das demais categorias são menos expressivas, entretanto, notam-se dois movimentos interessantes: o primeiro é que o número de pessoas desempregadas que se capacitaram aumentou consideravelmente entre 2013 até 2018, corroborando com o que já foi apresentado anteriormente, principalmente em relação à participação dos jovens; o segundo se refere à categoria de pessoas aposentadas, que, apesar das informações não constarem na Tabela 4, os dados indicam que a participação no período elevou-se em 108\%, ainda que sua representatividade seja baixa (menos que $2 \%$ ). 
No que se refere aos proprietários de empresas formais, informais e autônomos, alguns pontos devem ser destacados, como, por exemplo, a grande participação de microempreendedores individuais (76,9\%) e de empresários que possuíam empresa individual de responsabilidade limitada (14,8\%). Outra informação importante que complementa os dados expostos acima pode ser visualizada na Tabela 5, a qual apresenta o ramo e o tempo de atuação no mercado dos empresários capacitados.

Tabela 5 - Ramo e tempo de atuação no segmento dos empresários capacitados pelo PBNP - Núcleo Francisco Beltrão, no período 2013 - 2019

\begin{tabular}{|lcccccc|}
\hline Setor/Tempo & $\begin{array}{c}\text { Menos de } \\
6 \text { meses }\end{array}$ & $\begin{array}{c}\text { Entre 6 meses } \\
\text { e 1 ano }\end{array}$ & $\begin{array}{c}\text { Entre 1 e } \\
2 \text { anos }\end{array}$ & $\begin{array}{c}\text { Entre 2 e } \\
5 \text { anos }\end{array}$ & $\begin{array}{c}\text { Entre 5 e } \\
10 \text { anos }\end{array}$ & $\begin{array}{c}\text { Mais de } \\
10 \text { anos }\end{array}$ \\
\hline Comércio & $20,60 \%$ & $13,91 \%$ & $15,85 \%$ & $22,71 \%$ & $13,03 \%$ & $13,91 \%$ \\
\hline Indústria & $13,61 \%$ & $13,09 \%$ & $19,37 \%$ & $28,80 \%$ & $12,57 \%$ & $12,57 \%$ \\
\hline Serviço & $14,25 \%$ & $11,45 \%$ & $17,05 \%$ & $21,88 \%$ & $17,05 \%$ & $18,32 \%$ \\
\hline Total Geral & $17,27 \%$ & $12,93 \%$ & $16,84 \%$ & $23,44 \%$ & $14,32 \%$ & $15,19 \%$ \\
\hline
\end{tabular}

Fonte: Elaborado pelos autores.

ATabela 5 indica que o PBNP - Núcleo Francisco Beltrão conseguiu atender os empresários dos diversos ramos e tempo de atuação no mercado. Entre as empresas iniciantes, isto é, aquelas que possuem até 1 ano de existência, destaca-se a procura por capacitação pelos empresários do setor de comércio $(34,51 \%)$, seguido pelo setor da indústria (26,70\%). Quanto ao setor de comércio, tem-se percebido nos últimos anos uma elevação na procura por capacitação dos empresários ligados à alimentação (vendas de salgados, bolos, sanduíches, etc), vestuário (sendo estas tanto lojas físicas quanto as lojas online, sendo neste último caso verificado a predominância no uso das redes sociais para alavancar as vendas), além de pessoas que trabalham com artesanato e serviços de beleza em geral, sendo que a procura por capacitação nesses segmentos, em grande medida, foi dominada por empresários iniciantes. Sobre o setor da indústria, destaca-se o fato de que 28,80\% das empresas desse segmento capacitadas pelo PBNP - Núcleo Francisco Beltrão estavam em um estágio mais avançado de desenvolvimento, isto é, situavam-se na fase de amadurecimento ou de expansão. Porém, vale observar que, em comum à maioria delas, consta o fato de as mesmas apresentarem baixa intensidade tecnológica. Todavia, destaca-se que, mesmo diante da questão tecnológica, ao se expandirem, as empresas do ramo industrial são as que mais rapidamente geram empregos e salários atrativos.

Independente do ramo de atuação, no geral, 59,3\% dos empresários capacitados responderam ter uma renda média mensal de 1 a 3 salários mínimos, seguido por $29 \%$ com renda entre 4 e 6 salários mínimos. Entre os que responderam auferir renda superior a 10 salários mínimos, destacam-se os que atuam no setor de serviços, que, ao realizar um cruzamento de informações, identificou-se que são justamente aqueles com níveis de escolaridade mais elevados. Diante dessa estatística, o PBNP - Núcleo Francisco Beltrão reconhece que não 
pode modificar rapidamente a renda dos alunos capacitados, mas tem-se a consciência de que se pode trabalhar os módulos da forma mais didática e prática possível, contribuindo para que os mesmos consigam compreender os elementos básicos de gestão empresarial, mitigar os principais erros cometidos pelos empresários, e, por conseguinte, possibilitar que, ao menos, os mesmos consigam permanecer de forma ativa no mercado, obtendo alguma renda da atividade, mesmo sendo esta uma renda complementar ou de subsistência.

Além dos dados apresentados acima, os quais legitimam a intensa atuação do PBNP - Núcleo Francisco Beltrão na mesorregião Sudoeste do Paraná, vale destacar, ainda, outros três pontos. O primeiro diz respeito às feiras realizadas com os empresários capacitados no módulo de gestão estratégica, com o objetivo de possibilitar a eles a prática do que aprenderam durante o curso, além de facilitar a aproximação da empresa com o potencial cliente. Para tais atividades, procuram-se lugares estratégicos, com fluxo considerável de pessoas no horário noturno, enquadrando-se neste perfil de local as universidades e demais instituições de ensino da região. De acordo com Melo et al. (2017), os resultados das feiras têm sido bastante satisfatórios aos participantes. Tal afirmação é comprovada ao se verificar que ex-alunos procuram o projeto solicitando participar das demais edições. Além disso, os referidos autores relatam que alguns capacitados que tiveram sua primeira experiência de expor seu produto na feira realizada pelo PBNP, hoje já estão participando de exposições de portes maiores e por todo o território nacional.

O segundo ponto é relativo às parcerias realizadas entre o PBNP - Núcleo Francisco Beltrão e demais projetos de extensão da universidade. Nesse caso, citam-se duas parcerias principais, sendo a primeira com o Programa Patronato, o qual trabalha diretamente com assistidos do sistema penal e tem entre seus objetivos, oportunizar a inserção e/ou reinserção nos processos de educação formal e de qualificação profissional. A segunda parceria é com o Programa de Manipulação de Alimentos, no qual os alunos do curso de Nutrição da Unioeste orientam e capacitam os empresários do setor alimentício sobre a forma correta de como manusear e armazenar os alimentos. A sinergia gerada pela atuação conjunta entre os projetos beneficia de forma direta a sociedade e a Unioeste.

Como terceiro ponto, observa-se que como atividade inerente de um núcleo, no PBNP - Núcleo Francisco Beltrão são realizadas várias pesquisas acadêmicas. Em 2017, dados internos dos capacitados subsidiaram até uma pesquisa de pós-doutorado. Menciona-se, ainda, a publicação de um livro com 10 casos de sucesso, todos relatando a trajetória de alguns empresários capacitados pelo PBNP - Núcleo Francisco Beltrão. O referido livro tem sido usado como instrumento didático, auxiliando no trabalho de vários casos durante os módulos do curso, além de servir de inspiração e uma rica fonte de conhecimento aos novos capacitados.

\section{CONCLUSÕES}

Seguindo o protocolo do que se espera de um projeto de extensão e comprometido em transformar a realidade local, o PBNP - Núcleo Francisco Beltrão, amparado por uma equipe qualificada e uma ampla rede de 
inter-relações na região, empenhou-se em capacitar o maior número de empresários e futuros empresários da região Sudoeste do Paraná. Entretanto, tem-se consciência de que utilizar somente o número de empresários capacitados como métrica não é razoável, sendo tão ou mais importante verificar a qualidade da capacitação ofertada. Assim, ainda que os números apresentados pelo projeto sejam expressivos, observou-se que o retorno positivo daqueles que fizeram o curso sempre se manteve acima da média, dado que, ao final, muitos avaliaram que suas expectativas ficaram acima do esperado.

Além disso, verificou-se que o perfil dos capacitados é bastante heterogêneo. Todavia, nos anos recentes, tem-se percebido uma elevação da procura por capacitação em gestão empresarial pelas mulheres, com destaque para os setores de comércio e serviços. Mostrou-se, ainda, que o PBNP - Núcleo Francisco Beltrão tem buscado gerar novas experiências e conhecimentos aos seus capacitados, como é o caso da realização das feiras no módulo de gestão estratégica e das pesquisas e publicações realizadas ao decorrer do tempo. Não menos importante, destaca-se a parceria criada entre o PBNP - Núcleo Francisco Beltrão e demais projetos de extensão existentes na Unioeste, beneficiando duplamente a população atendida.

Perante o exposto e, ainda, diante do cenário econômico desafiador que se coloca, reforça-se a importância de atividades de extensão como as desenvolvidas pelo PBNP - Núcleo Francisco Beltrão. Contudo, sabe-se que problemas fiscais do estado poderão comprometer o financiamento do programa, chegando até mesmo a paralisar suas atividades. No entanto, é necessário observar que projetos como o Programa Bom Negócio Paraná, ao contrário do senso comum, deveria ter sua atividade expandida, uma vez que é justamente nesse momento que se eleva a busca por capacitação. Só assim é possível almejar que empresários e futuros empresários sintam-se mais seguros para abrirem ou, quando acharem prudente, ampliarem seus negócios, contribuindo para a geração de emprego, renda e, consequentemente, o desenvolvimento local.

Nesse sentido, demonstrou-se o resultado expressivo apresentado pelo PBNP - Núcleo Francisco Beltrão em sua missão de capacitar empresários e futuros empresários na região Sudoeste do Paraná. Entretanto, é certo que esses não são os únicos resultados. Por conseguinte, futuramente, pretende-se complementar uma agenda de pesquisa com a finalidade de relatar alguns resultados específicos, dentre eles: realizar um amplo levantamento entre os capacitados pelo PBNP - Núcleo Francisco Beltrão e avaliar a geração de emprego; verificar qual o impacto da capacitação sobre a renda pessoal; analisar junto à Fomento Paraná o número de projetos, quais as principais linhas de crédito buscadas, qual o valor médio financiado e o grau de inadimplência. Além disso e não menos importante, fazer um levantamento com cada membro que passou pelo projeto, visando compreender e enfatizar a importância da extensão na formação profissional, na intenção de demostrar a contribuição da experiência no PBNP e a receptividade e valorização dos mesmos no mercado de trabalho.

\section{Notas:}

1 Em 2019, com a reformulação da estrutura governamental, a SETI passou-se a chamar Superintendência Geral de Ciência, Tecnologia e Ensino Superior. No entanto, optou-se por manter o nome anterior (Secretaria de Ciência, Tecnologia e Ensino Superior) por compreender a maior parte do período de análise do artigo. 


\section{REFERÊNCIAS}

BRASIL. Lei Complementar n. ${ }^{\circ}$ 123, de 14 de dezembro de 2006. Institui o Estatuto Nacional da Microempresa e da Empresa de Pequeno Porte, e dá outras providências. Diário Oficial da União: seção 1, Brasília, DF, ano 143, n. 240, p. 1-10, 15 dez. 2006

BRASIL. Lei Complementar n. 128, de 19 de dezembro de 2008. Altera a Lei Complementar 123, de 14 de dezembro de 2006, e dá outras providências. Diário Oficial da União: seção 1, Brasília, DF, ano 145, n. 248, p. $1-7,22$ dez. 2008

BRASIL. Lei Complementar n. 155, de 27 de outubro de 2016. Altera a Lei Complementar n ${ }^{\circ} 123$, de 14 de dezembro de 2006, para reorganizar e simplificar a metodologia de apuração do imposto devido por optantes pelo Simples Nacional, e dá outras providências. Diário Oficial da União: seção 1, Brasília, DF, ano 153, n. 208, p. $1-4,28$ out. 2016

CELLARD, A. A análise documental. In: POUPART, J. et al. A pesquisa qualitativa: enfoques epistemológicos e metodológicos. Petrópolis, Vozes, 2008.

DALCIN, L; AUGUSTIN, R. B. O princípio da indissociabilidade entre ensino, pesquisa e extensão como paradigma de uma universidade socialmente referenciada. Revista Elo, diálogos em extensão, Viçosa, v. 5 , n. 3, p. 38-49, dez. 2016.

FORPROEX. I Encontro de Pró-reitores de extensão das universidades públicas brasileiras. 1987. Brasília. Disponível em: https://www.ufmg.br/proex/renex/images/documentos/1987-I-Encontro-Nacional-doFORPROEX.pdf. Acesso em: 16 de agosto de 2019.

FORPROEX - FÓRUM DE PRÓ-REITORES DE EXTENSÃO DAS UNIVERSIDADES PÚBLICAS BRASILEIRAS. Política Nacional de Extensão Universitária. 2012. Disponível em: https://www.ufmg.br/proex/ renex/images/documentos/2012-07-13-Politica-Nacional-de-Extensao.pdf. Acesso em: 16 de agosto de 2019.

GIL, A.C. Como elaborar projetos de pesquisa. $5^{\text {a }}$ ed. São Paulo: Atlas, 2010

GLOBAL ENTEPRENEURSHIP MONITOR - GEM. Empreendedorismo no Brasil 2017. Relatório Executivo. 2018. Disponível em: https://m.sebrae.com.br/Sebrae/Portal\%20Sebrae/Anexos/ Relat\%C3\%B3rio\%20 Executivo\%20BRASIL_web.pdf. Acesso em: 10 de julho de 2019

INSTITUTO BRASILEIRO DE GEOGRAFIAE ESTATÍSTICA. Estimativas da população residente para os municípios e para as unidades da federação com data de referência em $1^{\circ}$ de julho de 2019. 2019a. Disponível em: <https://www.ibge.gov.br/estatisticas/sociais/populacao/9103-estimativas-depopulacao.html?=\&t=resultados $>$. Acesso em: 5 de agosto de 2019

INSTITUTO BRASILEIRO DE GEOGRAFIAE ESTATÍSTICA. Demografia das empresas e estatísticas de empreendedorismo: 2017, Rio de Janeiro: IBGE, 2019b. 121p.

MELO, E. S.; BALDISSERA, H. C.; VIVIAN, F. C.; PAUCZINSKI, J. B.; FONTES, J. C.; HOLOSBACH, L. V.; ROSIN, L.; STOFFEL, J. A. Feiras de negócios dos empreendedores capacitados pelo Programa Bom Negócio Paraná no município de Francisco Beltrão. In: XVII Seminário de Extensão da Unioeste, 2017. Anais... Cascavel, 2017. p. 771-779 
OLIVEIRA, S.L. Tratado de metodologia científica. São Paulo: Pioneira, 1997.

RAMPAZZO, L. Metodologia científica: para alunos de graduação e pós-graduação. $7^{a}$ ed. São Paulo: Edições Loyola, 2013.

SEBRAE. Anuário do trabalho nos pequenos negócios: 2016. 9ª ed. São Paulo: DIEESE, 2018. p. 542.

SEBRAE. Pequenos negócios no Brasil. 2019. Disponível em: http://www.agenciasebrae.com.br/asn/Estados/ NA/Indicadores/Novo\%20MPE\%20Indicadores\%20-\%2015\%2008\%202018.pdf. Acesso em: 25 de junho de 2019.

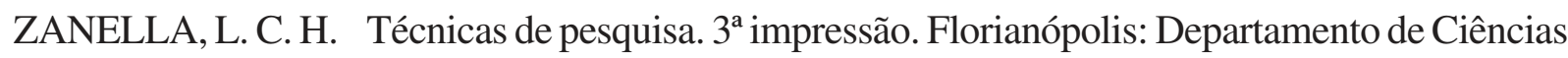
Contábeis - UFSC, 2013.

Submetido em: 28/08/2019 Aceito em: 01/11/2019 